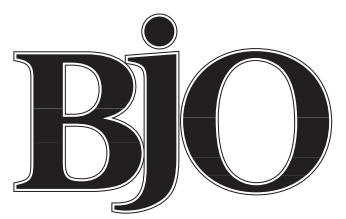

\title{
British Journal of Ophthalmology
}

It has been recognised for quite some time now that considerable differences occur in the treatments offered by doctors to apparently similar patients, both across countries and within countries. ${ }^{1-5}$ Reasons for studying these variations are based upon the wish to improve practice, to help to develop innovative aspects of care and also, very importantly, to monitor patient uptake and access to care. Variations in clinical practice occur despite the fact that healthcare professionals in their chosen clinical specialty basically share the same body of knowledge as a basis for their activities. Cataract surgery is apparently no exception, as shown in the paper by Norregaard et al, in this issue of the BfO (p1107), who have studied and described international variations in the indications for surgery.

Within the ophthalmic healthcare service there is an approach which we might adopt in contributing to the study of variations in ophthalmic care. We could:

(1) Lay more emphasis on the collection and use of basic clinical indicators such as visual acuity at the time of patient presentation, operation, and discharge

(2) Encourage interested colleagues to document the process of professional judgment involved in clinical decision making surrounding the use of clinical indicators

(3) Gradually broaden these indicators to include items on social and economic factors

(4) Contribute to the work of understanding the reasons for clinical variation at the level of profession, institution, and health system, nationally and internationally.

International comparisons of variations are of great interest. Our understanding of the underlying causes of variations, however, is problematic. This is particularly so at international level because of diversity of background and also because of issues surrounding definitions and standardisation of the methods that are used. Let us start in the UK by looking more closely at the variations in our own practice and relate these outwards to the experience of other countries. In doing so, the methods and information sources we develop, and on which we agree, will need to be carefully considered if we are to make our own contribution to this interesting area.

The study by Norregaard et al is in keeping with other reported studies (both national and international) on variations in clinical practice..$^{2-5}$ Their research on variation in indications for cataract surgery was, for the most part, focused on clinical factors relating to preoperative visual status and the coexistence of more than one eye disease. They conclude, however, that social, demographic, and societal factors were likely to be major contributory factors to the variations in practice that they observed. Yet very few of the economic and social factors that are put forward in the discussion section of this (and similar) articles are subject to the same level of investigation as the clinical factors within these studies.

As we move forward in developing methods for investigating variations in clinical practice in ophthalmology we can broaden the scope of the content at the same time. Work on differences in practice can either confine itself to reporting on those clinical factors that have been studied, or move forward in a truly multidisciplinary perspective in the study of clinical practice variations. Social and clinical epidemiological methods have a similar basis but if they are to be fused in clinical settings their different requirements for investigation have to be considered. An example here would be that of sample size, the importance of which we recognise yet do not necessarily find easy to calculate. We must now take account of the observations of social scientists and health economists that sample size estimates for clinical purposes may not be adequate or appropriate for investigating social variables.

If, as suggested by Norregaard et al, that contributory factors for variations in indications for surgery may be related to "patient demand", then broad socioeconomic profiling would help to investigate this issue. The authors also suggest that "access to care and practice style" may also be important contributory factors. Investigation of income levels and national charging policies could help to shed some light on these aspects.

While we can develop the methods for investigation, the ways and means of data acquisition are likely to be constrained by the budget available for information collection generally in the health sector. For the present therefore, and for some time ahead, we must maximise our use of available material. Our main sources of information must be those we can obtain from large routine datasets, supplemented by a few key socioeconomic and health policy factors. These data could be complemented by smaller in depth studies on specific issues-for example, outcomes assessment and operational research on clinical decision making surrounding choice of patient for surgery. For the latter to be a comprehensive assessment it must include monitoring of indicators, such as visual acuity, for those patients who present with self 
reported diminishing vision but are discharged to return at some distant time in the future or not at all.

Variations in thresholds for surgery raise important public health issues for investigation on equity, quality, and outcomes of care to which we as ophthalmologists can contribute with the help of epidemiology and the social sciences. In doing so, national variations could be quantified and monitored and used to inform allocation of resources for ophthalmic services that are both appropriate and equitable.

PARUL DESAI

University of Southampton Eye Unit, Southampton General Hospital, Tremona Road, Southampton SO16 6YD
ANGELA REIDY

Southampton General Hospital, Tremona Road,

Southampton SO16 6YD

1 Andersen TF, Mooney G. Medical practice variations: where are we? In: Andersen TF, Mooney G, eds. The challenges of medical practice variations. London: Macmillan Press Ltd, 1990:1-15.

2 Pearson RJC, Smedby B, Berfenstam R, et al. Hospital caseloads in Liverpool, New England and Uppsala. Lancet 1968;2:559-66.

3 Lewis CE. Variations in the incidence of surgery. N Engl f Med 1969; 281:880-4.

4 Bunker JP. Surgical manpower. A comparison of operations and surgeons in the United States and in England and Wales. N Engl f Med 1970;282:13544 .

5 Vayda E. A comparison of surgical rates in Canada and in England and Wales. $N$ Engl F Med 1973;289:1224-9.

\section{Lens cell growth and posterior capsule opacification: in vivo and in vitro observations}

It is now widely recognised that posterior capsule opacification (PCO) results from the proliferation and migration of lens epithelial cells (LECs) across the posterior capsule and is the most common cause of reduced visual acuity following modern cataract surgery. ${ }^{12}$ If strategies to prevent PCO are to be developed in a rational way then it will be necessary to understand the mechanisms underlying this relatively aggressive cell growth. Recently, significant advances have been made in the technologies that are required, on the one hand to study the basic molecular mechanisms of growth in vitro, ${ }^{3-5}$ and on the other to follow the patterns of cell movements within the capsular bag in vivo. ${ }^{6}$

The recent in vitro studies based on a human capsular bag model have led to a sea change in our views on the forces driving lens cell growth. Formerly it was held that lens cell growth could not be sustained without the addition of external growth factors and this led to an extensive search to define these exogenous factors (see Reid $^{7}$ for a review). However, most of these studies were carried out on lens cells cultured on plastic. Wormstone and colleagues ${ }^{5}$ have now shown that cells that remain in the capsular bag after surgery do not require factors exported from other cell types in order to survive and grow. They will rapidly cover the posterior capsule, induce wrinkling and cell aggregation and, indeed, produce many of the classic manifestations of PCO without any external influence. Furthermore, cells within young ( $<40$ years) capsular bags show more aggressive cell proliferation than that displayed by older cells ( $>60$ years) and this again mirrors the clinical situation. ${ }^{8}$ These recent data show that lens cells control growth within the capsular bag and this, in turn, has led to a search for autocrine growth factors. Preliminary analyses of the growth factors contained within capsular bags cultured for more than 100 days in a medium without additions ${ }^{9}$ indicate that lens cells can produce a range of growth factors including hepatocyte growth factor (HGF) and fibroblast growth factor (FGF). The presence of these growth factors is particularly interesting as both promote the proliferation and migration of epithelial cells. ${ }^{10} 11$

In vitro studies of human capsular bags with implanted PMMA lenses have also revealed that the matrix on which the cells are growing has a great effect on proliferation and migration. ${ }^{5}$ Cell movement onto the intraocular lens (IOL) is much more tentative than progression across the posterior capsule and cell regression is much more likely to occur. In fact, a certain degree of cell regression also occurs on the posterior capsule, especially once prominent wrinkles have formed and cell regression may hold the key as to why PCO presents as a serious visual problem for some patients but not for others.

Cell progression and regression can now be followed in vivo and Hollick and her colleagues show, in this issue of the $B F O$ ( $\mathrm{p} 1182$ ), that both aspects of cell behaviour depend on the material of the IOL. Most importantly, although cell growth and migration occurred in most cases over the first few weeks following cataract surgery, cell regression was found to occur over the following 2 years in $80 \%$ of patients receiving polyacrylic IOLs. This compared with regression rates of $8 \%$ and $15 \%$ for silicone and PMMA lenses respectively. The authors put forward several plausible explanations as to why this difference should occur. There does appear to be a stronger interaction between the capsule and acrylic IOLs than is the case with either PMMA or silicone lenses and they suggest that the interaction would not only mechanically compress the cells, but would impede the diffusion of nutrients to cells on the posterior capsule. Both of these effects could cause the cells to regress and atrophy.

There is now a very worthwhile hypothesis of a direct means of reducing PCO through the design of an IOL which maximises the interaction between the capsule and lens. Hollick et al suggest that as there is initially significant cell growth with acrylic IOLs, this interaction must take several weeks to develop. This hypothesis can only be rigorously tested in molecular and mechanistic terms under long term culture in vitro where not only can cell growth and regression be monitored but routine measurements could also be made of the extent of adhesion between the capsule and IOL. The in vitro models have certainly yielded valuable information concerning the relative efficacy of a range of strategies to prevent or reduce PCO. These have included a comparison of different clinical methodologies in current use, ${ }^{4}{ }^{12}$ and suggestions for innovative pharmacological methods for inhibiting PCO ${ }^{13}{ }^{14}$ It is now time for the in vitro experts to elucidate the basic mechanisms of IOL capsule interaction. Such a study may 
not only give useful information for future IOL design, but intriguingly might also shed some light on the question of why cell division is relatively inhibited and controlled in the whole lens yet so robust and aggressive in the open capsular bag. Both systems are subject to the same external growth factors, but, notably, the internal interactions, both chemical and physical, are quite different within the two systems.

GEORGE DUNCAN

University of East Anglia, School of Biological Sciences, Norwich NR4 7TJ

1 Apple DJ, Solomon KD, Tetz MR, et al. Posterior capsule opacification. Surv Ophthalmol 1992; 37:73-116.

2 Ohadi C, Moreira H, McDonnel PJ. Posterior capsule opacification. Curr Opin Ophthalmol 1991;2:46-52.

3 Nagamoto T, Bissen-Miyajima H. A ring to support the capsular bag after continuous curvilinear capsulorhexis. F Cataract Refract Surg 1994;20:41720.

4 Liu CSC, Wormstone IM, Duncan G, et al. A study of human lens cell growth in vitro: a model for posterior capsule opacification. Invest Ophthalmol Vis Sci 1996;37:906-14. 5 Wormstone IM, Liu CSC, Rakic J-M, et al. Human lens epithelial cell prolifPande MW, Ursell PG, Spalton DJ, et al. High resolution digital imaging of the posterior lens capsule after cataract surgery. $\mathcal{F}$ Cataract Refract Surg

7 Reid, TW. Growth control of cornea and lens epithelial cells. Prog Reg Eye Res 1994;13:507-54.

8 Moissiev J, Bartov E, Schochat A, et al. Long-term study of the prevalence of capsular opacification following extracapsular cataract extraction. $\mathcal{F}$ Cataract Refract Surg 1989;15:531-3.

9 Wormstone IM, Duncan G, Liu CSC, et al. Persistent lens cell activity throughout long-term culture of human capsular bags in protein-free medium. Invest Ophthalmol Vis Sci 1997;38:S212.

10 Gherardi E, Sharpe M, Sirulnik A, et al. Hepatocyte growth factor/scatter factor $(\mathrm{HGF} / \mathrm{SF})$, the c-met receptor and the behaviour of epithelial cells. In: Jones G, Wigley C, Warn RM, eds. Cell behaviour, adhesion and motility. SEB Symposium 1993;47:163-81.

11 McAvoy J, Chamberlain C. Fibroblast growth factor (FGF) induces different responses in lens epithelial cells depending on its concentration. Develent responses in lens epithe

12 Quinland M, Wormstone IM, Duncan G, et al. Phacoemulsification versus extracapsular cataract extraction: a comparative study of cell survival and growth on the human capsular bag in vitro. Brf Ophthalmol 1997;81:907-10.

13 Behar-Cohen FF, David T, D'Harmies F, et al. In vivo inhibition of lens regrowth by fibroblast growth factor 2-saporin. Invest Ophthalmol Vis Sci 1995;36:2434-48.

14 Duncan G, Wormstone IM, Liu CSC, et al. Thapsigargin coated intraocular lenses inhibit human lens cell growth. Nature Med 1997;3:1026-8.

\section{Contributors please note:}

Communications from the UK, Republic of Ireland, Australasia, Asia, Africa, Japan, and the Middle East should be sent to the Editor, British Journal of Ophthalmology, Department of Ophthalmology, University of Aberdeen, Medical School, Foresterhill, Aberdeen AB25 2ZD, Scotland, UK (Tel: 01224 663812; Fax: 01224 663832).

Communications from Western Europe, Eastern Europe, the former Soviet Union, and Scandinavia should be sent to Professor A Kijlstra, Associate editor, The Netherlands Ophthalmic Research Institute, PO Box 12141, Meibergdreef 9 , 1100 AC Amsterdam, Netherlands (Tel: +31 20 5664535; Fax: +31 20 6913401).

Communications from the USA, Canada, and South America should be sent to Professor C Hoyt, Associate editor, University of California, UCSF Ophthalmology Department, Pediatric Ophthalmology, 400 Parnassus Avenue, Room 702 A, Box 0344, San Francisco, CA 94143, USA (Tel: +415 476 1289/1921; Fax: +415 502 6468). 